\title{
Parental Perceived Travel Time to and Reported Use of Food Retailers in Association with School Children's Dietary Patterns
}

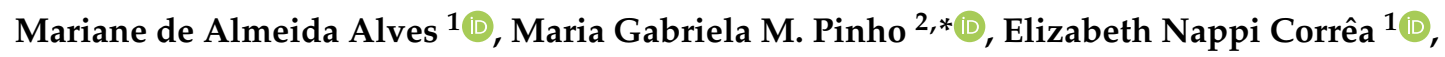 \\ Janaina das Neves ${ }^{1}$ (D) and Francisco de Assis Guedes de Vasconcelos ${ }^{1}$ (D) \\ 1 Department of Nutrition, Centre of Health Sciences, Federal University of Santa Catarina, Trindade, \\ Florianópolis, Santa Catarina 88040-900, Brazil; marianeaalves@hotmail.com (M.d.A.A.); \\ elizabeth.nappi@ufsc.br (E.N.C.); janaina.neves@ufsc.br (J.d.N.); f.vasconcelos@ufsc.br (F.d.A.G.d.V.) \\ 2 Department of Epidemiology and Biostatistics, Amsterdam Public Health Research Institute, Amsterdam \\ UMC, Vrije Universiteit Amsterdam, F wing, De Boelelaan 1089a, 1081 HV Amsterdam, The Netherlands \\ * Correspondence: m.matiasdepinho@vumc.nl
}

Received: 17 January 2019; Accepted: 1 March 2019; Published: 7 March 2019

check for updates

\begin{abstract}
Considering the association between the neighborhood food environment and individual eating behaviors, this study aimed to assess the association between parents' reported use of food facilities by their children, and parental perceived travel time to food facilities, with their children's dietary patterns. Parents reported the use of supermarkets, full-service and fast-food restaurants, and perceived travel time to these food retailers. To assess school children's food consumption, a previous day dietary recall was applied. Factor analysis was conducted to identify dietary patterns. To test the association between reported use and perceived travel time to food retailers and school children's dietary patterns, we performed multilevel linear regression analyses. Parents' reported use of supermarkets was associated with children's higher score in the "Morning/Evening Meal" pattern. The use of full-service and fast-food restaurants was associated with children's higher score in the "Fast Food" pattern. Higher parental perceived travel time to full-service and fast-food restaurants was associated with children's lower score in the "Fast Food" pattern. Although the use of full-service and fast-food restaurants was associated with a less healthy dietary pattern, the perception of living further away from these food retailers may pose a barrier for the use of these facilities.
\end{abstract}

Keywords: school children; dietary patterns; food environment; perceived travel time; use of food retailers

\section{Introduction}

There is a growing amount of evidence for an association between the neighborhood food environment and individual eating behaviors [1,2]. Considering that food choices are not only determined by individual behaviors, but are also influenced by social and physical environments [3], policies and interventions aimed at improving dietary patterns should take into account the environment in which people live, make food choices, and consume foods [4].

Exposure to the food environment comprises access to many different types of food retailers. The literature shows that supermarkets are an important source of food for many families [5] and living closer to a supermarket is associated with its use [6] and children's food choices [7]. Higher access to supermarkets is associated with lower consumption of fast food among adults [8] and with improved consumption of fruits and vegetables among children [9]. However, supermarkets are also associated with less desirable food choices such as increased consumption of processed products at the expense of minimally processed foods [10]. 
Furthermore, a higher proximity from a school or residence to fast-food restaurants is associated with unhealthier diets among students, including lower consumption of fruits and vegetables [11], higher portions of soda [11,12], and higher consumption of fatty foods [12]. Full-service restaurants are also an important component of the food environment that are very often neglected by food environment research [13]. From international literature, a link was observed in the exposure to full-service restaurants and a higher consumption of sugar-sweetened beverages [14], a lower consumption of fruits and vegetables [12,15], and higher calorie intake [16]. From a Brazilian perspective, buffet restaurants serving lunch might be a resource for maintaining a healthy diet outside the home, as these food retailers provide opportunities for a higher adherence to traditional Brazilian cuisine based on rice, beans, fresh meat, roots, and vegetables [17].

Exposure to food retailers can be assessed using different measures, tools, and methodological procedures, including metrics based on geographic information systems [1], which can be used, for instance, to objectively quantify the availability of food retailers in a neighborhood $[1,18]$. Another method to quantify exposure is the reported individual perceptions of his/her food environment [19]. While the use of objective measures is an important way to evaluate exposure to the food environment, residents' perceptions on the availability of food retailers may differ from what is objectively available [20]. The assumption that what is available (i.e., food retailers) is also used by individuals might not always be true, especially in urban areas featuring many available options to obtain food; therefore, a current gap in food environment research is the predominant lack of information on the use of facilities by the participants [21]. The perception of residents on the presence and distance to food retailers was indicated as an important methodological alternative to understand the influence of the environment on food behavior [22].

The aim of this study was to test the associations between parental reports of their children's use of food retailers and parental perceived travel time to food retailers with school children's dietary patterns. We also aimed to examine effect modification by income levels.

\section{Methods}

\subsection{Study Design, Sampling and Data Collection}

This cross-sectional study is part of a wider research project funded by the Brazilian National Council for Scientific and Technological Development (CNPq). The project aimed to analyze the tendency and prevalence of obesity and its associated factors among primary and secondary school children from seven to 14 years old from Florianópolis, southern Brazil.

Details on the sampling and design of the project were reported by previous studies [23,24]. In summary, a clustered sampling process was performed where the schools were divided into strata according to the administrative regions of the municipality of Florianópolis (central, north, east, and south island and mainland), and the type of school (public or private). In total, 30 schools (19 public and 11 private) were randomly selected from the strata.

Data were collected from September 2012 to June 2013 by trained researchers. Anthropometric measurements of school children (weight and height) were collected according to a protocol defined by the World Health Organization (WHO) [25], which uses reference curves based on the recommendations of Lohman, Roche, and Martorell (1988) [26]. A questionnaire with information on sociodemographic characteristics and a food acquisition profile was completed by the parents or guardians of the students.

The research protocol was approved by the Ethics Committee of the Federal University of Santa Catarina (UFSC) (ethical code: 120341/2012), in accordance with the standards established by the Resolution No. 466/2012 of the Brazilian National Health Council. The study was conducted in accordance with the Declaration of Helsinki, and only school children whose parents or guardians signed the informed consent term participated in the study. 


\subsection{Measures}

\subsubsection{Parents' Reports of Children's Usage of Food Retailers and Perceived Distance to Food Retailers}

We asked parents how often (never, weekly, twice a month, monthly, or rarely), in the past six months, their children used restaurants and fast-food restaurants. Fast-food restaurants may refer to both commonly known fast-food chains that sell burger-based meals and also to small local-owned food retailers that sell traditional baked and deep-fried snacks. Parents were also asked whether or not they buy foods to cook at home in the supermarket. Parents answered how far (minutes of walking distance) restaurants, fast-food restaurants, and supermarkets were located from their home. Response options in minutes were "one to five"; "six to 10 "; "11 to 15 "; "16 to 20 ", or "more than $20 \mathrm{~min}$ ".

Based on the data distribution, we categorized the reported frequency of use of restaurants and fast-food restaurants in the past six months into two categories ("did not use" or "used"). The use of supermarkets was originally asked in two categories ("did not use" or "used"). Parents' perceived travel time was also categorized into three categories: less than $10 \mathrm{~min}, 10$ to $20 \mathrm{~min}$, and more than 20 min of walking distance from their home.

\subsubsection{Dietary Patterns}

Food consumption information was collected using a qualitative food frequency questionnaire named QUADA (Portuguese acronym for "previous day food questionnaire"), an instrument developed and validated by Assis et al. [27], designed to assess the previous day food consumption of school children. QUADA presented higher kappa values for foods such as rice $(\mathrm{k}=0.92)$, beans $(\mathrm{k}=0.78)$, pasta $(\mathrm{k}=0.81)$, vegetable soup $(\mathrm{k}=0.82)$, and fruit $(\mathrm{k}=0.78)$, and lower values for foods such as sweets $(\mathrm{k}=0.38)$ and sweetened beverages $(\mathrm{k}=0.47)$. QUADA is composed of 21 commonly consumed foods, with the same 21 foods presented chronologically over six meals (breakfast, morning snack, lunch, afternoon snack, dinner, and evening snack) [27]. The children completed the questionnaires at school. Guided by a trained researcher assistant, the children were asked to indicate which of the 21 available foods they had eaten during each meal on the previous day.

We derived dietary patterns performing factor analysis via the principal component method. The sum of all foods consumed by the children in the previous day were entered into the factor analysis which was performed using a polychoric correlation matrix - the most suitable for our food consumption data [28]. The obtained factors were then transformed by orthogonal rotation varimax. To test whether our dietary data were suitable for factor analysis, we used the Bartlett's sphericity and Kayser-Meyer-Olkin (KMO) tests [29]. The criteria we used to retain the factors were an eigenvalue greater than 1, the scree plot charts, and the interpretability of the factors. Food groups were retained in the corresponding factor if they had a factor loading greater than or equal to \pm 0.3 .

\subsection{Covariates}

Sociodemographic characteristics were obtained from a questionnaire answered by the parents including information on children's sex (male or female), age (continuous), type of school (public or private), mother's self-reported weight and height (used to calculate mother's body mass index (BMI; continuous)), mother's education, and household income. Response options for mother's education were no formal education, incomplete secondary education, complete secondary education (equivalent to nine years of education), incomplete high school, complete high school (equivalent to 12 years of education), incomplete higher education, and complete higher education (university degree or higher). The variable maternal education was categorized into "complete secondary education", "complete high school", and "complete higher education". Household income was continuously assessed via a questionnaire referring to the sum of the monthly net income of all household residents with a paid job. We split the continuous variable of income into tertiles to test effect modification by income levels. School children's nutritional status was determined in terms of anthropometric measures; weight and height of school children were objectively measured and used to calculate the BMI. The school 
children's BMI was then classified into "normal weight" and "overweight" following the WHO age and sex-standardized cut-offs [30]. The percentage of underweight children was lower than $2 \%$; therefore, these children were incorporated into the normal-weight category.

\subsection{Statistical Analyses}

All the school children with complete food consumption data were kept in the analysis, resulting in an analytical sample of 2484 participants. Assuming that incomplete values were missing at random, we applied multiple imputation to all variables, except the outcome, using the predictive mean-matching method [31]. The percentage of missing values in our dataset ranged from $0.9 \%$ on children's BMI to $30.0 \%$ on the variable "perceived travel time to fast-food restaurants"; therefore, we imputed 40 datasets as recommended by Rubin [32] and Bodner [33]. For descriptive statistics, non-imputed data were used, and, for the regression models, we used pooled results from the 40 imputed datasets. We also present the regression models using non-imputed data as a sensitivity analysis (Tables S1 and S2, Supplementary Materials).

To test the association between parental perceived travel time to supermarkets, restaurants, and fast-food restaurants, we built six different models to test the associations between the three "perceived travel time" variables and reported usage of supermarkets, restaurants, and fast-food restaurants with dietary patterns. We tested for clustering at the school and at the grade levels across all models. Firstly, a random intercept for school was added, followed by a random intercept for grade. Using two-log likelihood tests, we found these two levels to be significant and, therefore, performed linear mixed-models analysis with participants (first level) clustered within grade (second level) and school (third level). We created product terms for the variables of use and income levels, as well as for the variable of perceived walking distance and income levels. To test effect modification, we added these product terms to the respective models. All models were a priori adjusted for age, children's nutritional status, mother's BMI and educational attainment, household income, and type of school. Questionnaire data were entered by two independent researchers and processed by Software EpiData ${ }^{\circledR}$ 3.2 (Epi Info Centers for Disease Control and Prevention, Atlanta, Georgia, United States). Descriptive and multilevel linear regression analyses, as well as multiple imputations, were performed using Stata ${ }^{\circledR} 13.0$ (Statistical Software for Professionals, College Station, TX, United States).

\section{Results}

Participants characteristics are described in Table 1. The mean age of school children was 10.4 years old, while the majority were girls $(56.5 \%)$ and were classified as normal weight (66.8\%). Most mothers had up to 12 years of education (46.1\%); the mean mothers' BMI was $25.2 \mathrm{~kg} / \mathrm{m}^{2}$. A large majority of parents reported the use of supermarkets in the past six months (95.7\%); restaurants and fast-food restaurants were reported to be used by $65.6 \%$ and $64.1 \%$ of parents, respectively. Most participants reported to live $10 \mathrm{~min}$ or less from a supermarket (40.6\%) and from a fast-food restaurant $(42.1 \%)$, whereas $40.2 \%$ reported to live more than 20 min away from a restaurant. 
Table 1. Descriptive characteristics of the participants. Florianópolis, Brazil, 2012-2013 ( $n=2484)$.

\begin{tabular}{|c|c|c|}
\hline \multirow[t]{2}{*}{ Characteristics } & \multicolumn{2}{|c|}{ Total Sample } \\
\hline & $n$ & Mean (SD) \\
\hline Age (years) & 2484 & $10.4(2.2)$ \\
\hline \multirow[t]{2}{*}{ Mother's BMI $\left(\mathrm{kg} / \mathrm{m}^{2}\right)$} & 2264 & $25.2(4.6)$ \\
\hline & $n$ & $\%$ \\
\hline \multicolumn{3}{|l|}{ Sex } \\
\hline Male & 1162 & 43.5 \\
\hline Female & 1322 & 56.5 \\
\hline \multicolumn{3}{|l|}{ Household income (net per month) } \\
\hline Tertile 1 (31-482 USD) & 712 & 31.9 \\
\hline Tertile 2 (483-917 USD) & 725 & 34.1 \\
\hline Tertile 3 (942-24,465 USD) & 694 & 34.0 \\
\hline \multicolumn{3}{|l|}{ Mother's education level } \\
\hline Complete secondary education & 630 & 24.5 \\
\hline Complete high school & 1058 & 46.1 \\
\hline Complete higher education & 679 & 29.4 \\
\hline \multicolumn{3}{|l|}{ Nutritional status } \\
\hline Normal weight & 1645 & 66.8 \\
\hline Overweight & 817 & 33.2 \\
\hline \multicolumn{3}{|c|}{ Parents' perceived travel time from home to supermarket } \\
\hline$\leq 10 \mathrm{~min}$ & 883 & 40.6 \\
\hline$>10$ to $\leq 20 \mathrm{~min}$ & 659 & 29.3 \\
\hline$>20 \mathrm{~min}$ & 693 & 30.2 \\
\hline \multicolumn{3}{|c|}{ Parents' perceived travel time from home to restaurant } \\
\hline$\leq 10 \mathrm{~min}$ & 606 & 33.6 \\
\hline$>10$ to $\leq 20 \mathrm{~min}$ & 461 & 26.2 \\
\hline$>20 \mathrm{~min}$ & 757 & 40.2 \\
\hline \multicolumn{3}{|c|}{ Parents' perceived travel time from home to fast food restaurant } \\
\hline$\leq 10 \mathrm{~min}$ & 688 & 42.1 \\
\hline$>10$ to $\leq 20 \mathrm{~min}$ & 482 & 27.2 \\
\hline$>20 \mathrm{~min}$ & 570 & 30.8 \\
\hline \multicolumn{3}{|c|}{ Parents' reported own use of supermarkets } \\
\hline Did not use & 91 & 4.3 \\
\hline Did use & 2284 & 95.7 \\
\hline \multicolumn{3}{|c|}{ Parents' report on children's use of restaurants } \\
\hline Children did not use & 845 & 34.4 \\
\hline Children did use & 1503 & 65.6 \\
\hline \multicolumn{3}{|c|}{ Parents' report on children's use of fast-food restaurants } \\
\hline Children did not use & 911 & 35.9 \\
\hline Children did use & 1424 & 64.1 \\
\hline
\end{tabular}

BMI = body mass index; USD = United States dollar.

The factor loadings for each food item in the corresponding dietary pattern are presented in Table 2. Five dietary patterns were derived from factor analysis: The first dietary pattern, named "Fast Food", was composed of French fries, soft drinks, pizza, packaged snacks, treats, and pasta, and it explained $12.5 \%$ of the data variance. The second dietary pattern, named "Morning/Evening Meal", was composed of cheese, milk, coffee, yogurt, and breads, and it explained $12.3 \%$ of data variance. These foods are usually consumed as breakfast or a morning snack, and, in the south of Brazil, a warm meal for dinner is commonly replaced by a meal composed of bread, cheese, milk, and coffee. The third dietary pattern, named "Traditional Brazilian", was composed of rice, beans, meat, and leafy greens, and it explained $10.5 \%$ of the data variance. The fourth dietary pattern, named "Healthy/Fresh Foods", was composed of juice, fruits, vegetables, leafy greens, soup, and fish, and it explained $9.9 \%$ of the data variance. The fifth dietary pattern, named "Bread and Chocolate Milk", was composed of chocolate milk and bread, and it explained $6.2 \%$ of the data variance. The total data variance explained by the five dietary patterns was $51.4 \%$. 
Table 2. Factor loadings a of dietary patterns among children and adolescents investigated. Florianópolis, Brazil, 2012-2013 ( $n=2484)$.

\begin{tabular}{lccccc}
\hline \multicolumn{1}{c}{ Food Groups } & Fast Food & $\begin{array}{c}\text { Morning/Evening } \\
\text { Meal }\end{array}$ & $\begin{array}{c}\text { Traditional } \\
\text { Brazilian }\end{array}$ & $\begin{array}{c}\text { Healthy/Fresh } \\
\text { Foods }\end{array}$ & $\begin{array}{c}\text { Bread/Chocolate } \\
\text { Milk }\end{array}$ \\
\hline Breads & -0.2524 & $\mathbf{0 . 3 8 5 2}$ & 0.0137 & 0.0675 & $\mathbf{0 . 5 5 9 9}$ \\
Chocolate milk & 0.2368 & -0.1373 & -0.0048 & 0.0920 & $\mathbf{0 . 6 8 7 0}$ \\
Milk & 0.0265 & $\mathbf{0 . 7 9 8 9}$ & 0.1080 & 0.1052 & -0.0357 \\
Coffee & -0.0725 & $\mathbf{0 . 7 7 0 3}$ & 0.0532 & -0.1155 & -0.1773 \\
Yoghurt & 0.2298 & $\mathbf{0 . 6 5 6 0}$ & 0.0152 & 0.1256 & 0.0211 \\
Cheese & 0.0717 & $\mathbf{0 . 8 0 3 3}$ & -0.0451 & 0.1036 & 0.1933 \\
Rice & -0.0465 & 0.0083 & $\mathbf{0 . 9 2 5 1}$ & 0.0034 & -0.0054 \\
Soft drinks & $\mathbf{0 . 6 8 9 8}$ & 0.0264 & 0.1005 & -0.2326 & 0.1400 \\
Treats & $\mathbf{0 . 5 3 9 6}$ & 0.0187 & 0.0409 & -0.0470 & 0.2058 \\
Chips & $\mathbf{0 . 6 2 5 2}$ & 0.0627 & -0.0345 & 0.0348 & 0.0625 \\
French fries & $\mathbf{0 . 7 2 8 2}$ & 0.0798 & 0.0825 & 0.0314 & -0.0862 \\
Pizza & $\mathbf{0 . 6 6 6 8}$ & 0.0192 & -0.2274 & -0.0019 & -0.0763 \\
Fruits & 0.0233 & 0.1199 & 0.0325 & $\mathbf{0 . 6 9 3 8}$ & -0.0403 \\
Beans & 0.0548 & 0.0455 & $\mathbf{0 . 8 1 7 2}$ & 0.1228 & -0.0273 \\
Pasta & $\mathbf{0 . 3 3 1 0}$ & 0.1290 & -0.2188 & 0.1168 & 0.1829 \\
Fish & 0.2855 & 0.0324 & 0.1986 & $\mathbf{0 . 3 4 6 5}$ & -0.2197 \\
Meat & 0.1271 & 0.1456 & $\mathbf{0 . 5 1 7 2}$ & -0.1101 & 0.2787 \\
Juice & -0.0996 & -0.0058 & -0.0162 & $\mathbf{0 . 7 2 1 3}$ & 0.0693 \\
Leafy greens & -0.1343 & 0.1110 & $\mathbf{0 . 3 8 0 7}$ & $\mathbf{0 . 5 0 1 5}$ & 0.1376 \\
Soup & 0.2081 & 0.0882 & -0.1974 & $\mathbf{0 . 4 6 8 2}$ & -0.3393 \\
Vegetables & -0.1405 & 0.1198 & 0.2450 & $\mathbf{0 . 5 7 4 8}$ & 0.2395 \\
\hline \% explained variation & 12.5 & 12.3 & 10.5 & 9.9 & 6.2 \\
\% of accumulated & 12.5 & 24.8 & 35.3 & 45.2 & 51.4 \\
explained variance & & & & & \\
\hline
\end{tabular}

${ }^{\text {a }}$ Highlighted values indicate a high correlation between the food group and the dietary pattern.

Table 3 shows the association of parents' reported use of food retailers and dietary patterns. We found that children whose parents reported using supermarkets had 0.19 higher score $(95 \%$ confidence intervals (CIs): 0.00, 0.38) in the "Morning/Evening Meal" pattern. Children whose parents reported using a restaurant had 0.09 higher score $(95 \%$ CIs: 0.01, 0.18) in the "Fast Food" pattern. Children whose parents reported using fast-food restaurants had 0.13 higher score in the "Fast Food" pattern (95\% CIs: 0.05, 0.20), 0.08 higher score (95\% CIs: 0.00, 0.16) in the "Bread and Chocolate Milk" pattern, and 0.09 lower score $(95 \%$ CIs: - 0.17, -0.02) in the "Morning/Evening Meal" pattern. Table 4 shows the association of parents' perceived travel time to the supermarket, full-service restaurants, and fast-food restaurants with dietary patterns. School children whose parents reported living more than 20 min away from a restaurant had 0.12 lower score (95\% CIs: $-0.21,-0.02)$ in the "Fast Food" pattern. School children whose parents reported living more than 20 min away from fast-food restaurants had 0.18 lower score (95\% CIs: -0.27, -0.08) in the "Fast Food" pattern. No association was found for parents' perceived travel time to supermarkets and dietary patterns. Parents' perceived travel time to any of the food retailers analyzed was not associated with the other four dietary patterns. We did not find any effect modification effects by income levels. 
Table 3. Coefficients and $95 \%$ confidence intervals (95\% CIs) as derived from multilevel linear regression analyses indicating the associations between parents' reported use of supermarkets and their children's usage of restaurant and fast-food restaurants with dietary patterns of school children. Florianópolis, Brazil, 2012-2013 ( $n=2484$ ).

\begin{tabular}{|c|c|c|c|c|c|}
\hline & $\begin{array}{l}\text { Fast Food } \\
\beta(95 \% \text { CIs })\end{array}$ & $\begin{array}{c}\text { Morning/Evening Meal } \\
\beta(95 \% \text { CIs) }\end{array}$ & $\begin{array}{c}\text { Traditional Brazilian } \\
\beta(95 \% \text { CIs) }\end{array}$ & $\begin{array}{c}\text { Healthy/Fresh Foods } \\
\beta(95 \% \text { CIs) }\end{array}$ & $\begin{array}{c}\text { Bread/Chocolate Milk } \\
\beta(95 \% \text { CIs })\end{array}$ \\
\hline \multicolumn{6}{|c|}{ Parents' reported own use of supermarkets } \\
\hline Did not use & 1 & 1 & 1 & 1 & 1 \\
\hline Did use & $-0.05(-0.25,0.15)$ & $0.19(0.00,0.38)$ & $-0.04(-0.24,0.15)$ & $0.12(-0.06,0.31)$ & $-0.03(-0.23,0.17)$ \\
\hline \multicolumn{6}{|c|}{ Parents' report on children's use of restaurants } \\
\hline Children did not use & 1 & 1 & 1 & 1 & 1 \\
\hline Children did use use & $0.09(0.01,0.18)$ & $-0.03(-0.12,0.05)$ & $-0.05(-0.13,0.04)$ & $0.06(-0.02,0.14)$ & $0.03(-0.05,0.12)$ \\
\hline \multicolumn{6}{|c|}{ Parents' report on children's use of fast-food restaurants } \\
\hline Children did not use & 1 & 1 & 1 & 1 & 1 \\
\hline Children did use & $0.13(0.05,0.20)$ & $-0.09(-0.17,-0.02)$ & $-0.01(-0.08,0.07)$ & $-0.03(-0.10,0.04)$ & $0.08(0.00,0.16)$ \\
\hline
\end{tabular}

All models were adjusted for age, type of school, nutritional status, maternal BMI, household income, and maternal education. Results in bold are statistically significant.

Table 4. Coefficients and 95\% confidence intervals (95\% CIs) as derived from multilevel linear regression analyses indicating the associations between parents' perceived travel time to supermarkets, restaurants, and fast-food restaurants with dietary patterns of school children in Florianópolis, Brazil, 2012-2013 ( $n=2484$ )

\begin{tabular}{|c|c|c|c|c|c|}
\hline & $\begin{array}{l}\text { Fast Food } \\
\beta(95 \% \text { CIs })\end{array}$ & $\begin{array}{c}\text { Morning/Evening Meal } \\
\beta(95 \% \text { CIs })\end{array}$ & $\begin{array}{c}\text { Traditional Brazilian } \\
\quad \beta(95 \% \text { CIs })\end{array}$ & $\begin{array}{l}\text { Healthy/Fresh Foods } \\
\quad \beta(95 \% \text { CIs })\end{array}$ & $\begin{array}{c}\text { Bread/Chocolate Milk } \\
\beta(95 \% \text { CIs) }\end{array}$ \\
\hline \multicolumn{6}{|c|}{$\begin{array}{l}\text { Parents' perceived travel time from home to: } \\
\text { Supermarkets }\end{array}$} \\
\hline$\leq 10 \min$ & 1 & 1 & 1 & 1 & 1 \\
\hline$>10$ to $\leq 20 \mathrm{~min}$ & $-0.04(-0.13,0.05)$ & $-0.05(-0.14,0.05)$ & $-0.01(-0.10,0.08)$ & $-0.04(-0.13,0.04)$ & $-0.07(-0.17,0.02)$ \\
\hline$>20 \mathrm{~min}$ & $-0.03(-0.12,0.06)$ & $-0.01(-0.11,0.08)$ & $0.08(-0.01,0.17)$ & $0.06(-0.03,0.15)$ & $-0.09(-0.18,0.01)$ \\
\hline \multicolumn{6}{|l|}{ Restaurants } \\
\hline$\leq 10 \min$ & 1 & 1 & 1 & 1 & 1 \\
\hline$>10$ to $\leq 20 \mathrm{~min}$ & $0.00(-0.10,0.11)$ & $0.04(-0.06,0.15)$ & $-0.01(-0.13,0.10)$ & $-0.01(-0.11,0.09)$ & $-0.04(-0.15,0.08)$ \\
\hline$>20 \mathrm{~min}$ & $-0.12(-0.21,-0.02)$ & $0.06(-0.04,0.15)$ & $0.04(-0.07,0.14)$ & $0.03(-0.07,0.12)$ & $-0.04(-0.14,0.06)$ \\
\hline \multicolumn{6}{|c|}{ Fast-food restaurants } \\
\hline$\leq 10 \min$ & 1 & 1 & 1 & 1 & 1 \\
\hline$>10$ to $\leq 20 \mathrm{~min}$ & $-0.05(-0.15,0.05)$ & $0.04(-0.06,0.14)$ & $-0.05(-0.15,0.05)$ & $0.06(-0.04,0.15)$ & $-0.03(-0.14,0.07)$ \\
\hline$>20$ min & $-0.18(-0.27,-0.08)$ & $0.05(-0.04,0.16)$ & $0.00(-0.10,0.10)$ & $0.06(-0.04,0.15)$ & $-0.06(-0.16,0.04)$ \\
\hline
\end{tabular}

All models were adjusted for age, type of school, nutritional status, maternal BMI, household income, and maternal education. Results in bold are statistically significant. 
Tables S1 and S2 (Supplementary Materials) show results from the sensitivity analysis where we performed the linear regression analyses using non-imputed data. In general, the results from sensitivity analyses were very similar to the main analyses where we used imputed data, with the exception of the association of use of fast-food restaurants and the "Morning/Evening Meal" pattern, which was significant in the main analysis $\beta-0.09(-0.17,-0.02)$ and became non-significant in the sensitivity analysis $\beta-0.08(-0.16,0.00)$. All other significant associations found in the main analysis were also found with the non-imputed dataset. Other few associations that were not significant in the main analysis became significant with non-imputed data, for instance, the positive association between the use of supermarkets and the "Healthy/Fresh Foods" pattern. However, due to the higher chance of bias present in the complete case analysis (sensitivity analysis), we only interpret results from the analysis using imputed datasets.

\section{Discussion}

We explored the associations between parents' reported use of food retailers by school children and parents' perceived travel time to food retailers with school children's dietary patterns. We found an association between the use of supermarkets and a higher score in the "Morning/Evening Meal" pattern. The use of full-service restaurants and fast-food restaurants was associated with a higher score in the "Fast Food" pattern. Higher perceived travel time to full-service restaurants and fast-food restaurants was associated with a lower score in the "Fast Food" pattern. We found no association between the use of food retailers and the "Traditional Brazilian" or the "Healthy/Fresh" foods pattern. No association was found either for perceived travel time to food retailers and the "Morning/Evening Meal", the "Traditional Brazilian", the "Healthy/Fresh Foods", or the "Bread and Chocolate Milk" patterns. No effect modification was found by income levels.

The fact that no association was found for the use of and perceived distance to food retailers and the "Traditional Brazilian" and the "Healthy/Fresh Foods" patterns is surprising, as we expected, for instance, that the use of and greater perceived distance to fast-food restaurants would be inversely associated with both "Traditional Brazilian" and the "Healthy/Fresh Foods" patterns. The hypothesis would be that traditional meals and fresh foods would more likely be consumed at home, meaning fewer visits to fast food restaurants. As shown by previous Brazilian studies, eating out of home is associated with the consumption of unhealthy foods (e.g., soft drinks, salty snacks, pizza, and sweets) [34,35], while a higher frequency of meals prepared at home is associated with lower calorie intake from foods rich in solid fat and sugar [36]. Yet, it could also be that the lack of variation for the use of supermarkets ( $96 \%$ reported using it) might have undermined our ability to detect any significant associations, which would mean that, even if an association was present, we would not be able to detect it.

The use of full-service restaurants and fast-food restaurants, which is linked to the consumption of foods away from home, was associated with the dietary pattern composed of less healthy foods. Powel and Nguyen investigated the association of eating in full-service restaurants and fast-food restaurants and increased energy intake [37]. They found that eating in full-service restaurants was associated with higher daily energy intake and higher intake of sugar-sweetened beverages among American children and adolescents (2-19 years old). A Brazilian study conducted by Andrade et al. [17] identified three dietary patterns for out-of-home food consumption: traditional meal, typical Brazilian breakfast/tea, and ultra-processed food. The authors found that children and adolescents aged 10-19 years had higher adhesion to the ultra-processed food pattern than older individuals [17]. This may indicate that, even when eating in restaurants that offer healthy options for lunch and dinner, such as the commonly found buffet-by-weight restaurants in Brazil, children and adolescents would choose less healthy options. Indeed, taste preferences for energy-dense foods could influence the selection of less healthy foods in restaurants offering this type of food [38].

The association between use of fast-food restaurants and the first dietary pattern was expected, as fast-food consumption is largely related to unhealthy dietary patterns. Fast-food consumption 
is associated with a lower overall diet quality in American children aged 2-18 years old; children characterized as high consumers of fast food presented a higher intake of sugar-sweetened beverages and French fries, and a lower consumption of fruits and vegetables when compared with children characterized as low consumers [39]. A positive association between sugar-sweetened beverage consumption and the use of fast-food restaurants was also identified in Chinese adolescents [40]. We previously observed a positive association between the use of fast-food restaurants and the consumption of ultra-processed foods with the same characteristics of food groups found in the "Fast Food" pattern [24].

Despite the positive association of the use of full-service restaurants and fast-food restaurants and a higher score in the "Fast Food" pattern, the perception of living further away from these outlets seems to have a protective effect on children's diet; higher perceived travel time to full-service restaurants and fast-food restaurants was negatively associated with the "Fast Food" pattern. Although the effect sizes found in our study are rather small, considering all individual and environmental factors that influence school children's dietary behavior, we consider those to be relevant effect sizes. Similar to our findings, Cutumisu et al. [41] found a positive association between the exposure to fast-food restaurants around schools and unhealthier food consumption at lunchtime, suggesting that the environment that school children are exposed to has an influence in their diet. The relationship between distance from fast-food restaurants and diet was also found in a study from the United States (US). In this study, children (four to 14 years) who lived closer to fast-food restaurants were less likely to consume fruits and vegetables [42].

Some studies explored the perceived availability of fast-food restaurants and found a positive association with a higher consumption of unhealthy foods among children and adolescents [12,43]. The majority of studies on food environment research used objectively measured metrics; however, literature using this methodology is inconsistent [44]. It may be that perceived access measures could produce more consistent results [3]. In addition, individual perception of the food environment is also likely to influence behavior, and it may reflect how people experience and interact with their neighborhoods. Thus, measures of perceived access to the food environment might be an important tool for food environment research and should also be taken into account when trying to understand the relationship between food environment and eating behaviors [45].

Our results are subject to some limitations, such as the fact that QUADA assesses the frequency of intake rather than quantity. Regarding the use of food retailers, when asking parents how often their children use restaurants and fast-food restaurants, we did not ask if the children were accompanied by the parents or not. This could lead to a mistaken report, especially from parents of older children. However, we assume that parents would know when their children visited restaurants, even when the parents were not present. The social desirability bias could be considered, especially among the older children, which could feel discouraged to report the consumption of less healthy foods in the presence of their peers and researchers. A common limitation with the use of food questionnaires is memory bias. Nonetheless, QUADA was developed to minimize difficulties related to children's assessment of portion size and to avoid lack of memory, since it accesses foods consumed in the previous day. In addition, during the administration of the questionnaire, researchers ensured that the students were situated in time and space while presenting the foods in the QUADA chart in a chronologic order. Although dietary intake from one day only may not be representative of the habitual individual intake, it is an advantage of our study that it included the coverage of different weekdays, including weekdays and Sundays [27]. We were also able to obtain a large sample size. This study is innovative for evaluating the information of both perceived travel time and the use of facilities, which is lacking in the current food environment research.

\section{Conclusions}

Our results indicate that, although the use of restaurants and fast-food restaurants may be associated with the "Fast Food" pattern, the perception of living further away from these food retailers 
might have a positive influence on school children's diet. These findings highlight the importance of evaluating the perceived food environment and the use of food retailers, which can provide a complementary understanding of the relationship between the food environment and diet.

Supplementary Materials: The following are available online at http:/ /www.mdpi.com/1660-4601/16/5/824/s1: Table S1: Coefficients and 95\% confidence intervals (95\% CIs) as derived from multilevel linear regression analyses indicating the associations between parents' reported use of supermarkets and their children's usage of restaurant and fast-food restaurants with dietary patterns of school children. Florianópolis, Brazil, 2012-2013 $(n=2484)$; Table S2: Coefficients and 95\% confidence intervals (95\% CIs) as derived from multilevel linear regression analyses indicating the associations between parents' perceived travel time to supermarkets, restaurants, and fast-food restaurants with dietary patterns of school children in Florianópolis, Brazil, 2012-2013 $(n=2484)$.

Author Contributions: Conceptualization, M.d.A.A. and M.G.M.d.P.; formal analysis, M.d.A.A. and M.G.M.d.P.; methodology, M.d.A.A. and M.G.M.d.P.; supervision, F.d.A.G.d.V.; writing一original draft, M.d.A.A., M.G.M.d.P., E.N.C., and J.d.N.; writing—review and editing, M.d.A.A., M.G.M.d.P., E.N.C., J.d.N., and F.d.A.G.d.V.

Funding: This work was supported by the National Council for Scientific and Technological Development (CNPq), a funding agency affiliated to the Ministry of Science, Technology, and Innovation of Brazil (MCTI/CNPq $\mathrm{n}$. 014/2011-grant number 483955/2011-6). M.G.M.d.P. has a grant from CNPq as part of the "Science Without Borders" Program, grant number 233850/2014-7. The content of this article reflects only the authors' views, and the funding agencies are not liable for any use that may be made of the information contained therein.

Acknowledgments: Many thanks to Joreintje D. Mackenbach for reading and providing useful suggestions on a draft of this manuscript.

Conflicts of Interest: The authors declare no conflicts of interest.

\section{References}

1. van der Horst, K.; Oenema, A.; Ferreira, I.; Wendel-Vos, W.; Giskes, K.; van Lenthe, F.; Brug, J. A systematic review of environmental correlates of obesity-related dietary behaviors in youth. Health Educ. Res. 2007, 22, 203-226. [CrossRef] [PubMed]

2. Smith, M.; Signal, L.; Edwards, R.; Hoek, J. Children's and parents' opinions on the sport-related food environment: A systematic review. Obes. Rev. Off. J. Int. Assoc. Stud. Obes. 2017, 18, 1018-1039. [CrossRef] [PubMed]

3. Engler-Stringer, R.; Le, H.; Gerrard, A.; Muhajarine, N. The community and consumer food environment and children's diet: A systematic review. BMC Public Health 2014, 14, 522. [CrossRef] [PubMed]

4. Larson, N.; Story, M. A review of environmental influences on food choices. Ann. Behav. Med. Publ. Soc. Behav. Med. 2009, 38 (Suppl. 1), S56-S73. [CrossRef] [PubMed]

5. Vogel, C.; Ntani, G.; Inskip, H.; Barker, M.; Cummins, S.; Cooper, C.; Moon, G.; Baird, J. Education moderates the association between supermarket environment and diet. Am. J. Prev. Med. 2016, 51, e27-e34. [CrossRef] [PubMed]

6. Gómez, M.I.; Ricketts, K.D. Food value chain transformations in developing countries: Selected hypotheses on nutritional implications. Food Policy 2013, 42, 139-150. [CrossRef]

7. Skidmore, P.; Welch, A.; van Sluijs, E.; Jones, A.; Harvey, I.; Harrison, F.; Griffin, S.; Cassidy, A. Impact of neighbourhood food environment on food consumption in children aged 9-10 years in the UK SPEEDY (Sport, Physical Activity and Eating behaviour: Environmental Determinants in Young people) study. Public Health Nutr. 2010, 13, 1022-1030. [CrossRef] [PubMed]

8. Athens, J.K.; Duncan, D.T.; Elbel, B. Proximity to Fast-Food Outlets and Supermarkets as Predictors of Fast-Food Dining Frequency. J. Acad. Nutr. Diet. 2016, 116, 1266-1275. [CrossRef] [PubMed]

9. Fiechtner, L.; Kleinman, K.; Melly, S.J.; Sharifi, M.; Marshall, R.; Block, J.; Cheng, E.R.; Taveras, E.M. Effects of Proximity to Supermarkets on a Randomized Trial Studying Interventions for Obesity. Am. J. Public Health 2016, 106, 557-562. [CrossRef] [PubMed]

10. Rischke, R.; Kimenju, S.C.; Klasen, S.; Qaim, M. Supermarkets and food consumption patterns: The case of small towns in Kenya. Food Policy 2015, 52, 9-21. [CrossRef]

11. Davis, B.; Carpenter, C. Proximity of fast-food restaurants to schools and adolescent obesity. Am. J. Public Health 2009, 99, 505-510. [CrossRef] [PubMed] 
12. Ho, S.Y.; Wong, B.Y.; Lo, W.S.; Mak, K.K.; Thomas, G.N.; Lam, T.H. Neighbourhood food environment and dietary intakes in adolescents: Sex and perceived family affluence as moderators. Int. J. Pediatr. Obes. IJPO Off. J. Int. Assoc. Stud. Obes. 2010, 5, 420-427. [CrossRef] [PubMed]

13. Sharkey, J.R.; Johnson, C.M.; Dean, W.R.; Horel, S.A. Focusing on fast food restaurants alone underestimates the relationship between neighborhood deprivation and exposure to fast food in a large rural area. Nutr. J. 2011, 10, 10. [CrossRef] [PubMed]

14. Laska, M.N.; Hearst, M.O.; Forsyth, A.; Pasch, K.E.; Lytle, L. Neighbourhood food environments: Are they associated with adolescent dietary intake, food purchases and weight status? Public Health Nutr. 2010, 13, 1757-1763. [CrossRef] [PubMed]

15. Leonard, T.; McKillop, C.; Carson, J.A.; Shuval, K. Neighborhood effects on food consumption. J. Behav. Exp. Econ. 2014, 51, 99-113. [CrossRef]

16. An, R. Fast-food and full-service restaurant consumption and daily energy and nutrient intakes in US adults. Eur. J. Clin. Nutr. 2016, 70, 97-103. [CrossRef] [PubMed]

17. Andrade, G.C.; da Costa Louzada, M.L.; Azeredo, C.M.; Ricardo, C.Z.; Martins, A.P.B.; Levy, R.B. Out-of-Home Food Consumers in Brazil: What do They Eat? Nutrients 2018, 10, 218. [CrossRef] [PubMed]

18. Thornton, L.E.; Pearce, J.R.; Kavanagh, A.M. Using Geographic Information Systems (GIS) to assess the role of the built environment in influencing obesity: A glossary. Int. J. Behav. Nutr. Phys. Act. 2011, 8, 71. [CrossRef] [PubMed]

19. Alber, J.M.; Green, S.H.; Glanz, K. Perceived and Observed Food Environments, Eating Behaviors, and BMI. Am. J. Prev. Med. 2018, 54, 423-429. [CrossRef] [PubMed]

20. Diez, J.; Valiente, R.; Ramos, C.; Garcia, R.; Gittelsohn, J.; Franco, M. The mismatch between observational measures and residents' perspectives on the retail food environment: A mixed-methods approach in the Heart Healthy Hoods study. Public Health Nutr. 2017. [CrossRef] [PubMed]

21. Clark, E.M.; Quigg, R.; Wong, J.E.; Richards, R.; Black, K.E.; Skidmore, P.M. Is the food environment surrounding schools associated with the diet quality of adolescents in Otago, New Zealand? Health Place 2014, 30, 78-85. [CrossRef] [PubMed]

22. Inglis, V.; Ball, K.; Crawford, D. Socioeconomic variations in women's diets: What is the role of perceptions of the local food environment? J. Epidemiol. Community Health 2008, 62, 191-197. [CrossRef] [PubMed]

23. Pinho, M.G.M.; Adami, F.; Benedet, J.; Vasconcelos, F.A.G. Association between screen time and dietary patterns and overweight/obesity among adolescents. Revista de Nutrição 2017, 30, 377-389. [CrossRef]

24. Corrêa, E.N.; Retondario, A.; Alves, M.A.; Bricarello, L.P.; Rockenbach, G.; Hinnig, P.F.; Neves, J.; Vasconcelos, F.A.G. Utilization of food outlets and intake of minimally processed and ultra-processed foods among 7 to 14-year-old schoolchildren. A cross-sectional study. Sao Paulo Med. J. 2018. [CrossRef]

25. World Health Organization. Physical Status: The Use and Interpretation of Anthropometry; WHO: Geneva, Switzerland, 1995.

26. Lohman, T.; Roche, A.; Martorell, R. Anthropometric Standardization Reference Manual; Human Kinetics Books: Champaign, IL, USA, 1988.

27. Assis, M.d.A.A.; Benedet, J.; Kerpel, R.; Vasconcelos, F.d.A.G.; Di Pietro, P.F.; Kupek, E. Validação da terceira versão do Questionário Alimentar do Dia Anterior (QUADA-3) para escolares de 6 a 11 anos. Cadernos de Saúde Pública 2009, 25, 1816-1826. [CrossRef] [PubMed]

28. Holgado-Tello, F.P.; Chacón-Moscoso, S.; Barbero-García, I.; Vila-Abad, E. Polychoric versus Pearson correlations in exploratory and confirmatory factor analysis of ordinal variables. Qual. Quantity 2008, 44, 153. [CrossRef]

29. Gleason, P.M.; Boushey, C.J.; Harris, J.E.; Zoellner, J. Publishing nutrition research: A review of multivariate techniques-part 3: Data reduction methods. J. Acad. Nutr. Diet. 2015, 115, 1072-1082. [CrossRef] [PubMed]

30. de Onis, M.; Onyango, A.W.; Borghi, E.; Siyam, A.; Nishida, C.; Siekmann, J. Development of a WHO growth reference for school-aged children and adolescents. Bull. World Health Org. 2007, 85, 660-667. [CrossRef]

31. Moons, K.G.; Donders, R.A.; Stijnen, T.; Harrell, F.E., Jr. Using the outcome for imputation of missing predictor values was preferred. J. Clin. Epidemiol. 2006, 59, 1092-1101. [CrossRef] [PubMed]

32. Rubin, D.B. Multiple Imputation for Nonresponse in Surveys; Wiley J \& Sons: New York, NY, USA, 2009.

33. Bodner, T.E. What Improves with Increased Missing Data Imputations? Struct. Eq. Model. Multidiscip. J. 2008, 15, 651-675. [CrossRef] 
34. Bezerra, I.N.; Moreira, T.M.V.; Cavalcante, J.B.; Souza, A.M.; Sichieri, R. Consumo de alimentos fora do lar no Brasil segundo locais de aquisição. Revista de Saúde Pública 2017, 51, 1-8. [CrossRef]

35. Gorgulho, B.M.; Fisberg, R.M.; Marchioni, D.M.L. Away-from-home meals: Prevalence and characteristics in a metropolis. Revista de Nutrição 2014, 27, 703-713. [CrossRef]

36. Prado, B.G.; Hinnig, P.F.; Tanaka, L.F.; Latorre, M.R.D.O. Qualidade da dieta de escolares de 7 a 10 anos do município de São Paulo: Associação com o número e os locais de refeições. Revista de Nutrição 2015, 28, 607-618. [CrossRef]

37. Powell, L.M.; Nguyen, B.T. Fast-food and full-service restaurant consumption among children and adolescents: Effect on energy, beverage, and nutrient intake. JAMA Pediatr. 2013, 167, 14-20. [CrossRef] [PubMed]

38. Shepherd, J.; Harden, A.; Rees, R.; Brunton, G.; Garcia, J.; Oliver, S.; Oakley, A. Young people and healthy eating: A systematic review of research on barriers and facilitators. Health Educ. Res. 2006, 21, 239-257. [CrossRef] [PubMed]

39. Poti, J.M.; Duffey, K.J.; Popkin, B.M. The association of fast food consumption with poor dietary outcomes and obesity among children: Is it the fast food or the remainder of the diet? Am. J. Clin. Nutr. 2014, 99, 162-171. [CrossRef] [PubMed]

40. Lee, Y.H.; Chiang, T.C.; Liu, C.T.; Chang, Y.C. Investigating adolescents' sweetened beverage consumption and Western fast food restaurant visits in China, 2006-2011. Int. J. Adolesc. Med. Health 2018. [CrossRef] [PubMed]

41. Cutumisu, N.; Traore, I.; Paquette, M.C.; Cazale, L.; Camirand, H.; Lalonde, B.; Robitaille, E. Association between junk food consumption and fast-food outlet access near school among Quebec secondary-school children: Findings from the Quebec Health Survey of High School Students (QHSHSS) 2010-2011. Public Health Nutr. 2017, 20, 927-937. [CrossRef] [PubMed]

42. Futrell Dunaway, L.; Carton, T.; Ma, P.; Mundorf, A.R.; Keel, K.; Theall, K.P. Beyond Food Access: The Impact of Parent-, Home-, and Neighborhood-Level Factors on Children's Diets. Int. J. Environ. Res. Public Health 2017, 14, 662. [CrossRef] [PubMed]

43. Choo, J.; Kim, H.J.; Park, S. Neighborhood Environments: Links to Health Behaviors and Obesity Status in Vulnerable Children. West. J. Nurs. Res. 2017, 39, 1169-1191. [CrossRef] [PubMed]

44. Keane, E.; Cullinan, J.; Perry, C.P.; Kearney, P.M.; Harrington, J.M.; Perry, I.J.; Layte, R. Dietary quality in children and the role of the local food environment. SSM Popul. Health 2016, 2, 770-777. [CrossRef] [PubMed]

45. Chen, X.; Kwan, M.P. Contextual Uncertainties, Human Mobility, and Perceived Food Environment: The Uncertain Geographic Context Problem in Food Access Research. Am. J. Public Health 2015, 105, 1734-1737. [CrossRef] [PubMed]

(C) 2019 by the authors. Licensee MDPI, Basel, Switzerland. This article is an open access article distributed under the terms and conditions of the Creative Commons Attribution (CC BY) license (http://creativecommons.org/licenses/by/4.0/). 